\title{
Effect of CKD and Fiber Glass on Impact Strength
}

\section{and Hardness of Polyester Composites}

\author{
Kh. Th. Hassan \\ Department of Physics, College of Science, Anbar University \\ Ramadi, Anbar, Iraq
}

Copyright (C) 2014 Kh. Th. Hassan. This is an open access article distributed under the Creative Commons Attribution License, which permits unrestricted use, distribution, and reproduction in any medium, provided the original work is properly cited.

\begin{abstract}
Cement Kiln dust (CKD) is a byproduct materials, formed in the kiln during the cement clinker production operation. . In this paper order to meet environmental requirements CKD used as filling particles to fabricated composite with polyester resin. Small percentage of fiber glass added to the CKD/Polyester composite to enhance their mechanical properties. Impact and hardness tests for composite showed that the presence of CKD improved both impact strength and hardness for the composite, while fiber glass shows significant increasing in impact strength of composite but has no longer influence on the hardness.
\end{abstract}

Keywords: (CKD), Polyester, fiber glass, Impact strength, hardness

\section{Introduction}

Recycling means any recovery operation by which waste materials are reprocessed into products, materials or substances whether for the original or other purposes. On the other hand, Recovery means any operation the principal result of which is waste serving a useful purpose by replacing other materials which would otherwise have been used to fulfill a particular function, or waste being prepared to fulfill that function, in the plant or in the wider economy. Byproduct dust (CKD) is a particulate mixture of partially calcined and unreacted raw feed, clinker dust ash, enriched with alkali sulfates, halides and other volatiles. 
In general, the waste material divided into two main types which are hazardous and non-hazardous. Non-hazardous waste is those do not meet the US Environmental Production Agency (EPA)'s definition of hazardous waste and are not municipal waste. EPA categorized (CKD) as a special non-hazardous material $[1,2]$. Some of the CKD is recycled back again with the clinker but the amount are limited by the alkalinity requirements for Portland cement. However, most of CKD is disposed.

In 2006 USA generated 2563000 metric tons of CKD, 1403000 metric tons were reused beneficially while 1160000 metric tons send to landfill and in Iraq there were about $640000[3,4,5]$.

Many researches done to recycle CKD, most of these researches concentrated on use of Cement Kiln dust as filler on asphalt cement or as stabilizer agent. Mixing of CKD and the waste of shingles with the soil in the asphalt cement improve the compressive strength for it [6]. On the other hand, add CKD with the other filler at different concentrations can improve the tensile strength of asphalt concrete [5]. Also, using CKD with Homra in conventional ceramic as composite contents can improve their mechanical and thermal properties [7]. Thaha investigated replacement of Portland cement with four different types of CKD in the development of low-strength materials. The results showed that the different percentages of CKD can developed the properties the asphalt [8].

In the resent years some researches done by using Cement Kiln Dust to reinforcement polymers. Study on the effect mixing (CKD) fine particle with epoxy resin reveals that the presence of these particles enhances the sliding wear resistance of epoxy resin [9].

In the resent paper, Firstly CKD used as a filling particles to reinforcement polyester resin alone and secondly mixed with a small percentage of fiber glass with different percentages. Impact strength and hardness measured for the samples to investigate the influenced of adding the CKD on the mechanical properties of the polymers.

\section{Experimental}

\subsection{Fabrication of composites}

Cement kiln dust gotten from kubaisa cement plant $(180 \mathrm{~km})$ west of Baghdad. Cement dust powder passing sieve no.8 $(2.36 \mathrm{~mm})$ to get rid from impurities and to got same particles size. Polyester resin (density $1.1 \mathrm{~g} / \mathrm{cm}^{3}$ ) was mixed with Cobalt Octoate which acts as accelerator of polymerization. (2wt. \%) of Methyl ethyl ketone peroxide (MEKP) was added to the polyester resin which is acts as a catalyst and initiator of polymerization to the resin. After that, CKD powder mixed with polyester resin by the mixer for $5 \mathrm{~min}$. The hand lay-up molding is used to prepare the composite. Five fabricated composites were prepared with 
different percentage of CKD powder and polyester resin. Anther samples fabricated by adding fiber glass to $\mathrm{CKD} /$ Polyester mixture to fabricated composites same to three of above $\mathrm{CKD}$ /polyester composite percentages. Also, hand lay-up molding used and the mold subjected to (10 ton) pressers to complete the fabrication process. Table (1) illustrates different samples contents and percentages.

Table 1: composite contents wt. \%

\begin{tabular}{cccc}
\hline Sample name & CKD wt. \% & Up wt. \% & G wt. \% \\
\hline A1 & 30 & 70 & 0 \\
A2 & 20 & 70 & 10 \\
A3 & 22 & 70 & 8 \\
A4 & 24 & 70 & 6 \\
B1 & 40 & 60 & 0 \\
B2 & 34 & 60 & 6 \\
B3 & 32 & 60 & 8 \\
B4 & 30 & 60 & 10 \\
C1 & 50 & 50 & 0 \\
C2 & 42 & 50 & 8 \\
C3 & 37 & 50 & 10 \\
C4 & 35 & 50 & 13 \\
D1 & 70 & 30 & 0 \\
E1 & 80 & 20 & 0 \\
\hline
\end{tabular}

\subsection{Izod Impact test}

Izard impact test used to measure the impact strength of the composites. All

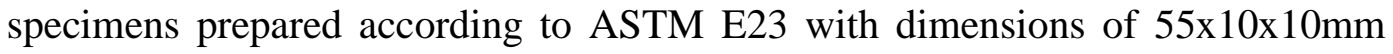
V-notch: $2 \mathrm{~mm}$ deep, with $45^{\circ}$ angle and $0.25 \mathrm{~mm}$ radius along the base. The test carried out three times for each sample and the rate of the result was taken. From energy absorbed in breaking the specimen, impact strength calculated according to the following relation

Izod Impact strength $\left(\mathrm{J} / \mathrm{cm}^{2}\right)=\frac{\text { Energy absorbed in joules }}{\text { Width of notched face } \mathrm{x} \text { Length below the notch }}$

\subsection{Hardness test}

Shore D hardness tester used to measure the hardness for the samples. The samples fabricated with a completely flat surface before carried out the test which is very necessary to get good results. Hardness test carried out according to ASTM D2240. The specimen is first placed on a hard flat surface. The indenter for the instrument is then pressed into the specimen making sure that it is parallel to the surface. The hardness is read within one second of firm contact with the specimen. The test specimens are generally $6.4 \mathrm{~mm}$ thick. 


\section{Result and Discussion}

\subsection{Impact strength}

Fig.1. exhibit the effect of CKD filler concentrations in impact strength of polyester composite. It was found that the impact strength of the composite increased with the increasing of the CKD fillers. The best Impact strength result obtained for the samples of (40wt. \%) CKD. However, increasing of CKD fillers percentage in the polyester composite deceased the impact strength of the composite and at the percentage of $(80 \mathrm{wt}$. \%) CKD the impact strength dropped to the value less than the impact strength value of the small concentrations (30wt. $\%)$. It was clearly to observe from the figure that the best result take place with the fillers concentrations between (40 to $50 \mathrm{wt}$ \%) of CKD. The increment in impact strength of polyester composite with the CKD fillers is due to the capability of the fillers to resist the propagation of the crack before the facture take place. In addition, good interaction between the fillers particles and the polyester matrix would increase the strength of the composite. This is attributed to that the interlocking of polyester into the pores region of the fillers [10]. Fig.2. illustrate impact strength for three weight percentages of CKD fillers and fiber glass according to the results obtained from the last curve. Fiber glass percentages differ from (6 to $13 \mathrm{wt}$. \%) for these three reinforcement materials. Test result shows increasing in impact strength with the increasing of fiber content for this small limit of fiber glass weight percentage unless for the $30 \%$ wt. which decreased with the increasing in the fiber glass contents. Among all the samples best result was for A4 sample $(13.277 \mathrm{~J} / \mathrm{cm})$ which unexpected due to the results obtained in the fig.1. This could be attributed due to the good interaction among the contents in this weight percentage which was reflected on the very good resistance against crack propagations Results for $\mathrm{C} 4, \mathrm{~A} 3, \mathrm{~A} 2$ and $\mathrm{C} 3$ respectively supported this assumption. So the best impact strength results for $\mathrm{CKD} /$ fiber glass/polyester composite for little fiber glass contents could be in that range of weight concentrations. 


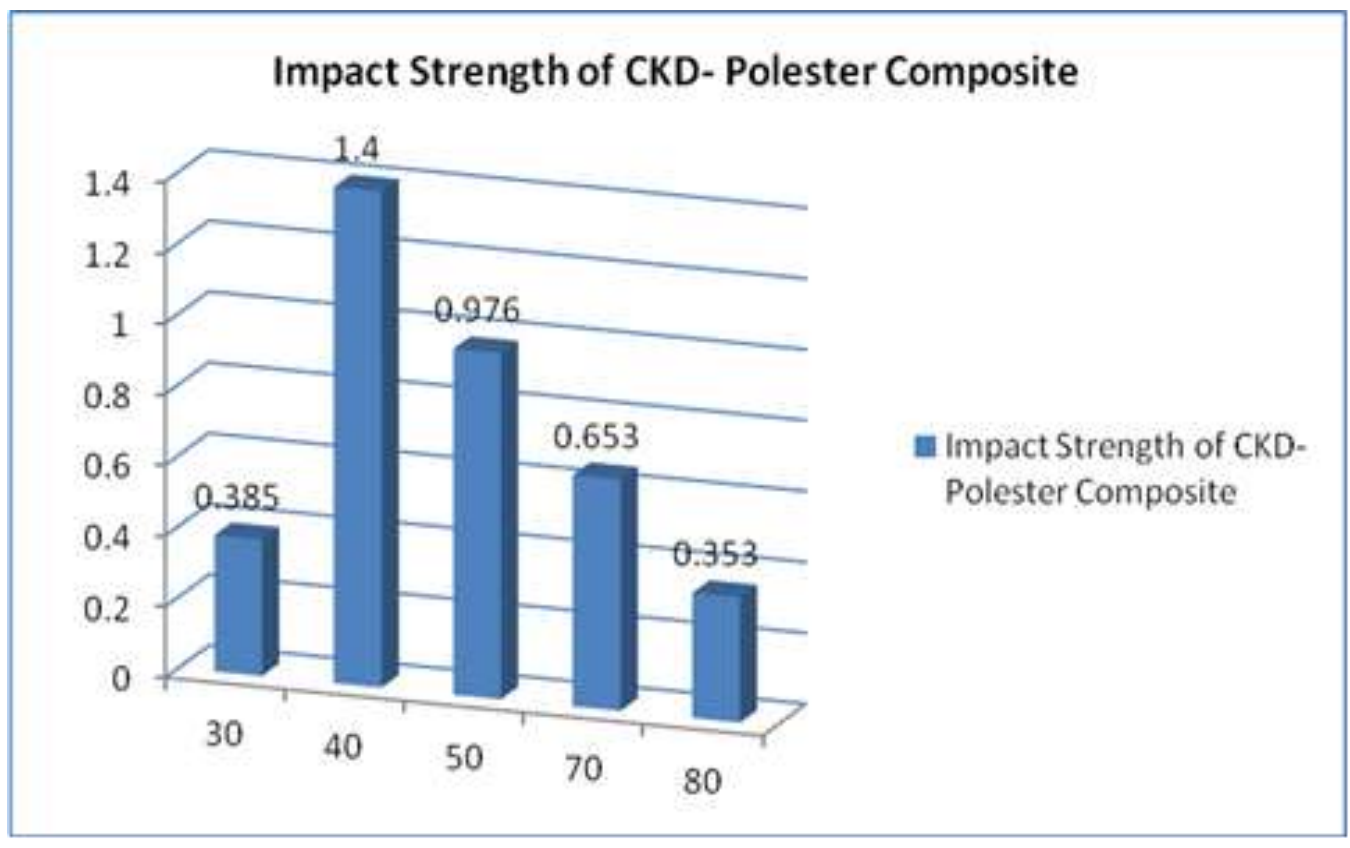

Fig.1.Impact strength of CKD/Polyester composites

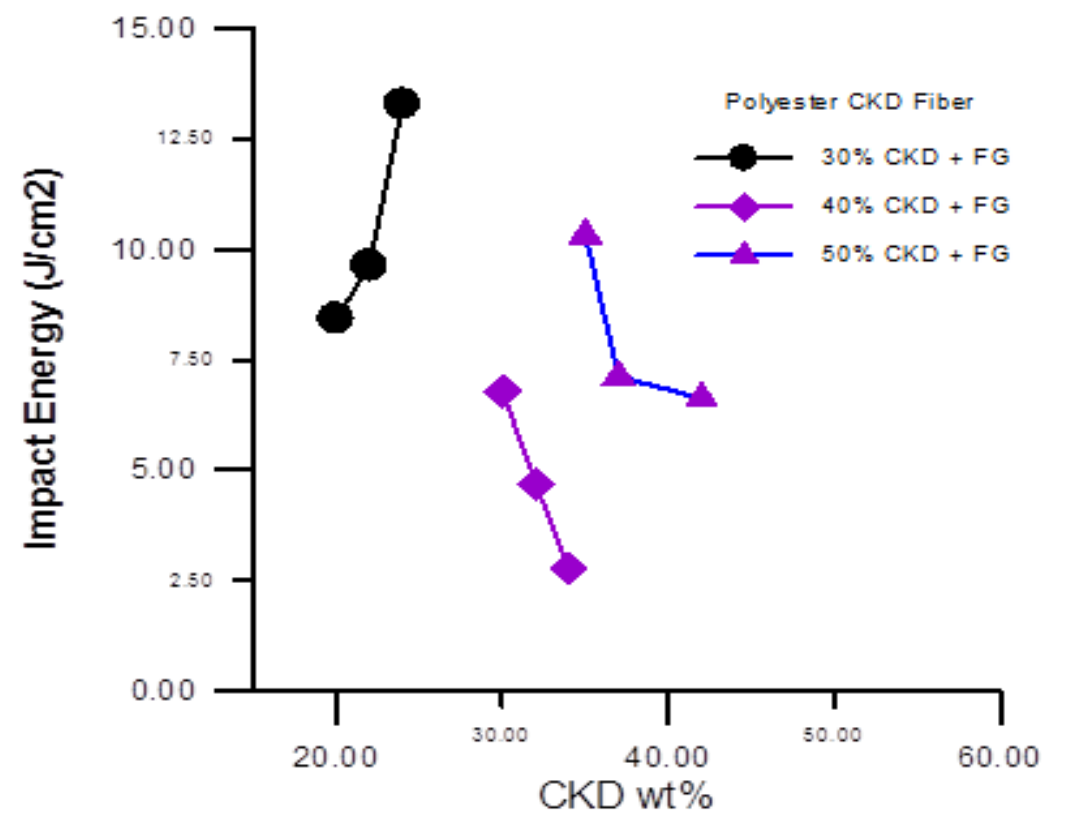

Fig.2.Impact strength of CKD/Fiber glass/polyester composites

\subsection{Hardness}

Hardness gives good information on the microstructure of polymer composite. So, good mixing give homogenous composite. The result shows that an increase in CKD fillers increased the hardness of the composite. Fig.3. shows the change of 
the hardness with the change in the CKD weight concentration. However, good result obtained from the specimens B1, C1 respectively. On the other hand, other specimen shows hardness results closed to those best results. Fig.4. illustrate the hardness test results for CKD/Fiber glass/ composite. The results show that the adding of fiber glass to the composite no longer increased the hardness to the composite. Best result obtained for $\mathrm{B} 4, \mathrm{C} 4$, and $\mathrm{B} 3$ respectively, these result indicated that the good hardness obtained was to the same composites weight percentage for the low fiber glass contents that showed good impact results.

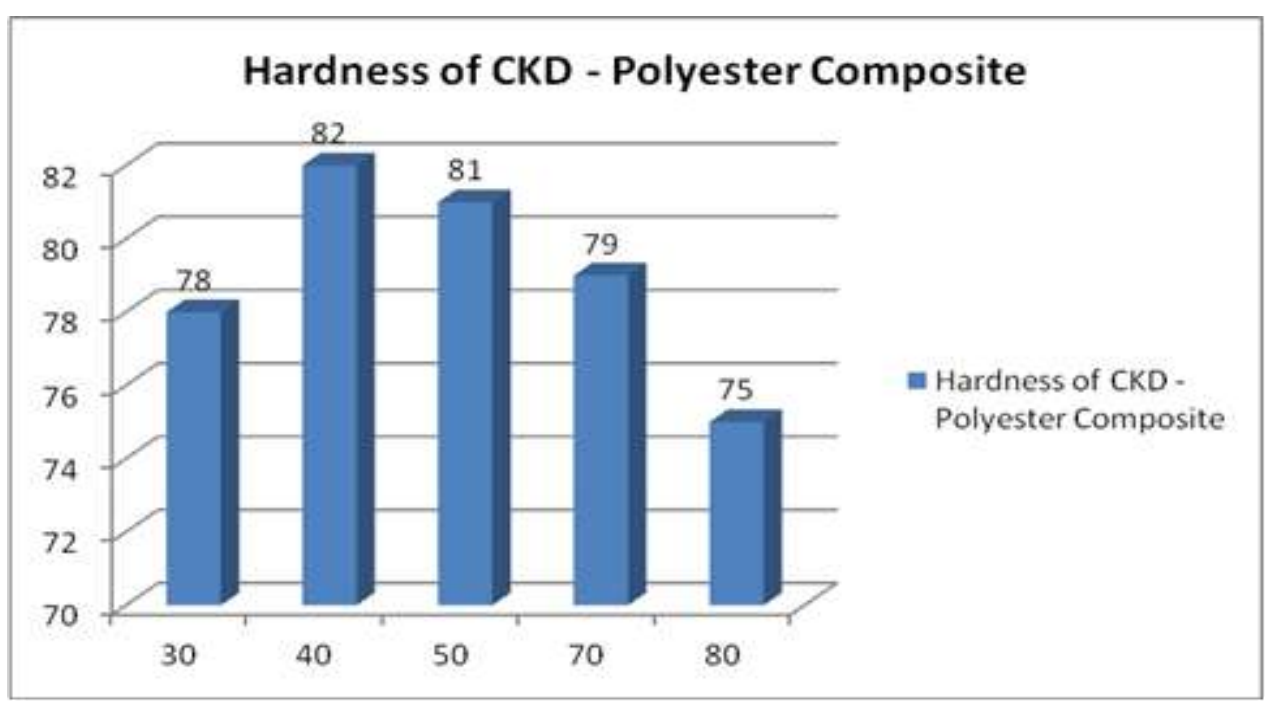

Fig.3. Hardness of CKD/polyester composites

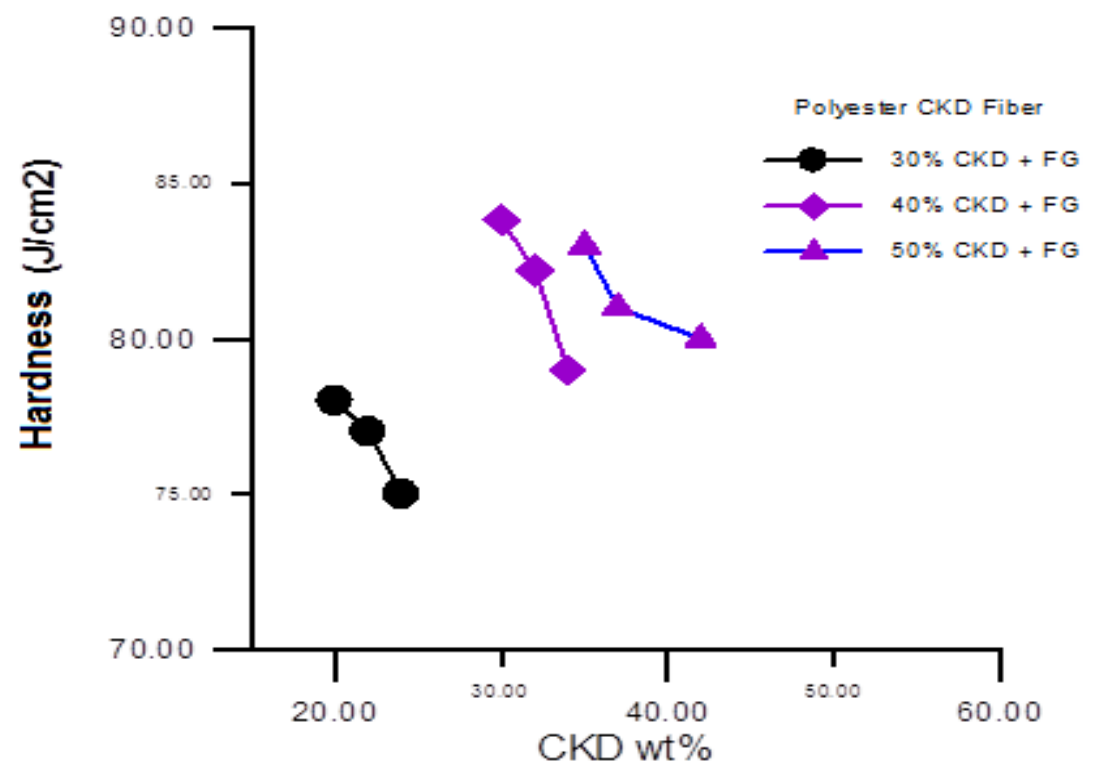

Fig.4. Hardness of CKD/Fiber glass/polyester composites 


\section{Conclusions}

In general, the present research shows that the cement kiln dust can be used as good fillers to product new composite and reduced the cost of materials. The results indicated that for this small range of fiber glass percentage between (6-13wt.), the best results obtained from CKD fillers contained in polyester composite lied in the range of $(22-37 \% \mathrm{wt})$ CKD weight percentages. Adding CKD to polyester resin increased both impact strength and the hardness for the composite while, adding fiber glass has significantly increased the impact strength of composite but has no influence in the hardness of composite.

\section{References}

[1] BS EN 179-1: CEM 1, Health and safety information, Portland cement, data sheet, Lafarge cement UK Ltd, Birmingham, UK (2012)

[2] Environment agency, Guidance for the recovery and disposal of hazardous and non-hazardous waste, integrated pollution prevention and control, IPPC S5.06, 4 (2004), 5-7.

[3] J. S. Baugh, T. B. Edil, Suitability of Cement Kiln Dust for Reconstruction of Roads, Portland Cement Association, Skokie, Illinois, USA, (2008), 1-7

[4] Wayne S. Adaska, Donald H. Taubert, Beneficial uses of cement kiln dust, PCA $50^{\text {th }}$ cement industry technical conference, (2008), 1-5 doi:10.1109/CITCON.2008.24 ISBN

[5] Dr. Talal H. Fadhil, Salih S. Jasim, Dr. Khalil E. Aziz, Ahmed S. Ahmed "Influence of using White Cement Kiln Dust as a Mineral Filler on Hot Asphalt Concrete Mixture Properties" , International journal of civil engineering and technology, 4(2013), 87-96.

[6] A. Ahmed, M. Shehata, and S.Easa, Use of Factory-Waste Shingles and Cement Kiln Dust to Enhance the Performance of Soil used in Road works, Advances in Civil Engneering, (2009), 9. doi:10.1155/2009/143750

[7] H.H.M. Darweesh, E.M. Negim and M.M.S. Wahsh, Densification and Thermo mechanical Properties of Conventional Ceramic Composites Containing Two Different Industrial Byproducts, American-Eurasian Journal of Scientific Research, 7(2012), 123-130 
[8] W. Thaha, Development of controlled low strength materials using cement kiln dust, M.S. thesis, Civil Engineering Department, Ryerson University, Toronto, (2005)

[9] A. D. Bhatt, A. Patnaik, A. Satapath, and Siddhartha, A study on Modified Mechanical Wear Characteristic of Epoxy-Particulate Filled Homogenous Composites and their Functionally Graded Materials, Journal of Tribology, 133 (2010), 11. doi:10.1115/1.4002543

[10] A. Abu bakar and L.F. Low, Fracture Toughness and Impact strength of Hollow Epoxy Particles-Toughened Polyester Composite, Sains Malaysiana 4(2013), 443-448.

Received: November 1, 2013 